\title{
Evaluating feasibility and acceptability of a group WHO trans-diagnostic intervention for women with common mental disorders in rural Pakistan: a cluster randomised controlled feasibility trial
}

\author{
M. N. Khan ${ }^{1 *}$, S. U. Hamdani ${ }^{2,3}$, A. Chiumento ${ }^{3}$, K. Dawson ${ }^{4}$, R. A. Bryant ${ }^{4}$, M. Sijbrandij ${ }^{5}$, H. Nazir ${ }^{2}$,

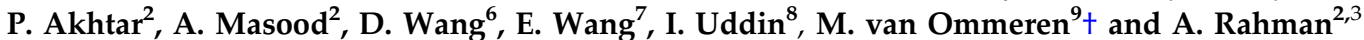 \\ ${ }^{1}$ Khyber Medical University, Institute of Public Health E Social Sciences (IPHESS), 10-B, Near ICMS, Phase V, Hayatabad, Peshawar, Pakistan \\ ${ }^{2}$ Human Development Research Foundation, Islamabad, Pakistan \\ ${ }^{3}$ University of Liverpool, Liverpool, UK \\ ${ }^{4}$ University of New South Wales, Sydney, Australia \\ ${ }^{5}$ VU University Amsterdam, Amsterdam, The Netherlands \\ ${ }^{6}$ Liverpool School of Tropical Medicine, Liverpool, UK \\ ${ }^{7}$ Queen Mary University of London, UK \\ 8 Bacha Khan Medical College, Mardan, Pakistan \\ ${ }^{9}$ Department of Mental Health and Substance Abuse, World Health Organisation, Geneva, Switzerland
}

Aims: The aim of this feasibility trial was to evaluate the feasibility and acceptability of the locally adapted Group Problem Management Plus (PM+) intervention for women in the conflict affected settings in Swat, Pakistan.

Methods: This mixed-methods study incorporated a quantitative component consisting of a two arm cluster randomised controlled feasibility trial, and qualitative evaluation of the acceptability of the Group PM+ to a range of stakeholder groups. For the quantitative component, on average from each of the 20 Lady Health Workers (LHWs) catchment area (20 clusters), six women were screened and recruited for the trial with score of $>2$ on the General Health Questionnaire and score of $>16$ on the WHO Disability Assessment Schedule. These LHW clusters were randomised on a 1:1 allocation ratio using a computer-based software through a simple randomisation method to the Group $\mathrm{PM}+$ intervention or Enhanced Usual Care. The Group PM+ intervention consisted of five weekly sessions of $2 \mathrm{~h}$ duration delivered by local non-specialist females under supervision. The primary outcome was individual psychological distress, measured by levels of anxiety and depression on the Hospital Anxiety and Depression Scale at $7^{\text {th }}$ week after baseline. Secondary outcomes include symptoms of depression, post-traumatic stress disorder (PTSD), general psychological profile, levels of functioning and generalised psychological distress. Intervention acceptability was explored through in-depth interviews.

Results: The results show that lay-helpers with no prior mental health experience can be trained to achieve the desired competency to successfully deliver the intervention in community settings under supervision. There was a good intervention uptake, with Group PM+ considered useful by participants, their families and lay-helpers. The outcome evaluation, which was not based on a large enough study to identify statistically significant results, indicated statistically significant improvements in depression, anxiety, general psychological profile and functioning. The PTSD symptoms and depressive disorder scores showed a trend in favour of the intervention.

Conclusion: This trial showed robust acceptance in the local settings with delivery by non-specialists under supervision by local trained females. The trial paves the way for further adaptation and exploration of the outcomes through larger-scale implementation and definitive randomised controlled trials in the local settings.

Received 9 January 2017; Accepted 9 June 2017; First published online 10 July 2017

Key words: Depression, group therapy, other psychosocial techniques/treatments, randomised controlled trials, women.

*Address for correspondence: M. N. Khan, Khyber Medical University, Institute of Public Health \& Social Sciences (IPH\&SS), 10-B, Near ICMS, Phase V, Hayatabad, Peshawar, Pakistan.

(Email: drnasim@kmu.edu.pk)

† There was an error in the author's name that has now been corrected. A corrigendum has been published providing details.

\section{Introduction}

Research on mental health problems ${ }^{1}$ following humanitarian emergencies ${ }^{2}$ has focused on post-traumatic stress disorder (PTSD) (Inter-Agency Standing Committee, 2007; George et al. 2012). However, a broad range of 
mental health consequences are recognised (World Health Organization, 2007). While the prevalence rates of mental health problems during and after humanitarian emergencies tend to be higher compared with other populations, there is considerable variation (Inter-Agency Standing Committee, 2007; Steel et al. 2009). The average rates for depression and PTSD range between 15 and 20\% (Steel et al. 2009). Women are especially vulnerable to common mental disorders due to lack of resources, low education, limited social support and gender-based violence (Allden et al. 1996; Bhui et al. 2003; Ellsberg et al. 2008). A recent survey (current study site) found $38 \%$ of women were psychologically distressed, and associated with previous exposure to conflict-related trauma and major stressors such as death/disability of a significant other, financial constraints, accommodation difficulties and interpersonal problems, including marital issues (Khan et al. 2015).

The evidence base regarding psychological treatments for mental health problems specifically related to trauma is mounting; however, the majority of this research has been conducted in high-income settings or through specialised professionals (Tol et al. 2011; Tol et al. 2013). In order to be scalable in humanitarian emergencies, it is important to establish whether such interventions remain effective when delivered by nonspecialists under supervision. Such interventions have received significant attention as part of the global mental health research agenda (Kakuma et al. 2011). These interventions should be brief and simple, so that they can be delivered by people in the community (Rahman et al. 2008). Additionally, interventions should address a range of outcomes (trans-diagnostic), including physical functioning and common mental health and psychosocial problems.

The WHO, as part of its mhGAP (Mental Health Gap Action Programme), has developed guidance for humanitarian settings and is testing psychological interventions delivered by non-specialists, including Problem Management Plus (PM+) (Dawson et al. 2015; Ventevogel et al. 2015). PM+ has been developed for adults affected by symptoms of common mental health problems, including depression, anxiety and those related to practical issues such as unemployment and interpersonal relationship difficulties, within contexts following exposure to an emergency.

In order to fit different service, contexts and beneficiary groups, it will be important to have both individual and group versions of PM+. This will aid accessibility by a

\footnotetext{
${ }^{1}$ Mental health problems: Mental health issues such as anxiety, stress, PTSD and depression.

${ }^{2}$ Humanitarian emergencies: Armed conflicts and natural disasters (including food crises) with large segments of populations at acute risk of death, immense suffering and/or losing their dignity.
}

range of target groups. The group format not only draws on the same strategies as the individual version of PM+, but also has the benefits of peer interaction and the potential for group members to be therapeutic agents to each other (Yalom \& Leszcz, 2005). A meta-analysis suggests that group psychotherapeutic interventions based upon cognitive behavioural approaches are as effective as individual interventions at 6-month follow-up (Cuijpers et al. 2008). Due to the ability to reach larger numbers of people, the group format offers a potentially scalable approach that may also be a cost-effective means of intervention.

The aim of this study was to evaluate the feasibility and acceptability of the Group PM+ intervention in rural Swat, which has recently been exposed to conflict. A key feature was to explore the feasibility of nonspecialist delivery of the intervention in collaboration with the Lady Health Workers (LHWs) programme ${ }^{3}$.

\section{Methods \\ Study design}

This mixed-methods study incorporates a two arm cluster randomised controlled feasibility trial, and qualitative evaluation of the acceptability of Group $\mathrm{PM}+$ intervention to a range of stakeholders.

\section{Settings and participants}

Swat is a rural district in the northern part of the Khyber Pakhtunkhwa Province, Pakistan. The majority of the population (86\%) lives rural (Pakistan Bureau of Statistics, 2016). Since 2007 Swat has witnessed widespread conflict/militancy. During the active conflict between the army and militants in 2009, nearly 2.5 million people of the district were internally displaced across Pakistan (Bile \& Hafeez, 2009). In July 2009, these displaced persons were asked to repatriate after the Government declared the area safe, although continued military presence and sporadic conflicts between militants and security agencies continues to create social unease (Rome, 2010).

The current trial was conducted from 21st March until 12th August, 2015 in Qambar Union Council (UC), a rural conflict-affected area in Swat. Each UC has a Basic Health Unit (BHU) staffed by a physician, a Lady Health Visitor (primary healthcare worker stationed at a health unit and providing maternal and child health services), a vaccinator, a midwife

\footnotetext{
${ }^{3}$ LHWs programme was started in 1994 to provide health education, promote healthy behaviours, supply family planning methods and provide basic curative services in the communities.
} 
and LHWs. LHWs are trained to provide mother and child healthcare and education to a catchment area of approximately 1000 people or 150 homes, conducting monthly routine health visits (Hafeez et al. 2011). Given their existing roles, LHWs provided a link between Group PM+ facilitators/delivery agents and women in the community, overcoming a significant access barrier.

Participants were females aged 18 years or above, referred for screening based on the judgment of their LHW that they were psychologically distressed. Participants who scored above 2 on the General Health Questionnaire (GHQ) and above 16 on the WHO Disability Assessment Schedule (WHO-DAS) were invited to participate in the trial by trained assessment team. Assessment team members were females from the local community. Those Women with imminent suicide risk, cognitive impairment (e.g., severe intellectual disability or dementia) or mental disorder (psychotic disorders, substance-dependence) were excluded.

As a cluster-randomised control trial the unit of randomisation was the LHWs catchment area. Of the 24 LHWs in Qambar UC, 20 LHWs were eligible for randomisation (Fig. 1), which was carried out by an independent researcher. Based on 1:1 allocation ratio, 10 LHWs were randomised to the intervention and 10 to Enhanced Usual Care (EUC) ${ }^{4}$ arm. On average six women were recruited for the trial from each LHW catchment area. When randomised into the intervention arm, the LHW along with the lay-helper informed the participant of the schedule for five consecutive weekly Group PM+ sessions, with the first session scheduled not longer than 2 weeks after the preintervention assessment. The two lay-helpers carried out half of the intervention sessions each.

\section{Intervention}

Group problem management plus

$\mathrm{PM}+$ is a WHO psychological intervention developed on evidence of established problem solving, counselling and behavioural techniques (Dawson et al. 2015). Group PM+ is an adaptation of the individual intervention. The multicomponent nature of $\mathrm{PM}+$ allows for many symptoms of common mental health disorders to be addressed with the one intervention (i.e. trans-diagnostic). The manual has been translated into Urdu and Pashtu, and culturally adapted to the Swat setting. This study is the first testing of Group

\footnotetext{
${ }^{4}$ Enhanced Usual Care (EUC): Usual care was enhanced by training primary care staff and ensuring referral pathways for common mental health problems.
}

$\mathrm{PM}+$, which comprises five weekly sessions each lasting $2 \mathrm{~h}$, inclusive of breaks. All LHWs in the intervention arm were provided a half-day training session by the lay-helpers regarding their roles and responsibilities in the trial. LHWs initially served to facilitate introduction of lay-helpers to community, encourage participant attendance, and provide a space in which to conduct sessions. LHWs were present when Group PM+ sessions were conducted, although they were not active facilitators of the intervention content.

Group PM+ was delivered by local female layhelpers with 16 years of education (graduates) and with no formal training of or prior experience in mental health. Lay-helpers and participants were gender matched to enhance acceptability and ensure researcher safety (Craig et al. 2000). The training and supervision of lay-helpers followed an apprenticeship model (Murray et al. 2011), which involves moving the primary delivery of healthcare from specialists such as psychiatrists and psychologists to lay-helpers, and building skills through on-the-job training. Three non-specialist supervisors (HN, PA and AM) and two female lay-helpers received 6 days training by the Master Trainer (KD). Training covered knowledge of common mental disorders, basic counselling and group management skills, the Group PM+ intervention and self-care strategies. This was followed by four weeks of practice cases with weekly group supervision through Skype (2-3 h duration) by the 3 supervisors. This group supervision model was continued throughout the trial, providing opportunities for peer learning and collective problem-solving. Before delivering Group PM+ as part of the trial, lay-helpers completed competency assessments (explained below under process evaluation). These were developed specifically for $\mathrm{PM}+$ and involved role-plays that were scored on fidelity to the treatment, competency of intervention delivery and counselling skills.

\section{Enhanced usual care (EUC)}

In Swat, treatment-as-usual in primary healthcare centres (PHCs) to individuals with common mental disorders usually consists of: (a) no treatment, (b) placebo-based care, as evidence-based mental health care is not currently available in PHCs, or (c) referral to the District Headquarter Hospital (DHQ) for specialised psychiatric care. For this study, care was enhanced in two ways: (a) LHWs received training in primary care referral pathways for treatment of common mental disorders; and (b) primary care physicians received the training in assessment and treatment of common mental disorders routinely taught by our partner, the WHO Collaborating Center in Rawalpindi, Pakistan. Both of these trainings were delivered by the Swat District 


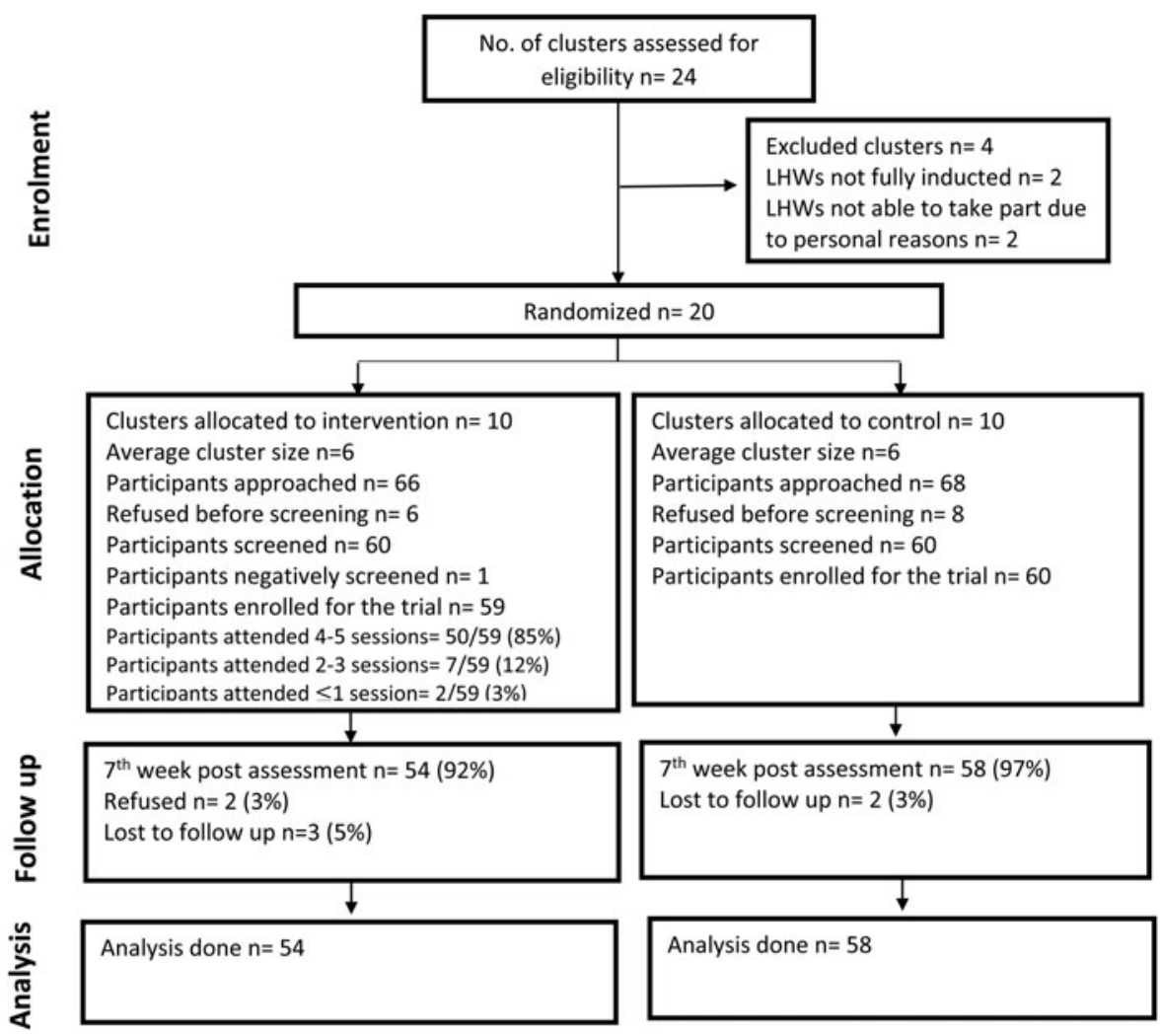

Fig. 1. Consort flow diagram of the feasibility trial.

Psychiatrist in separate half-day sessions. During the study any EUC participants with severe psychiatric disorders (e.g., psychosis) or problems (e.g., suicidality) that required immediate specialist treatment and follow-up were referred to the DHQ or BHU, depending upon their needs.

\section{Measures}

Assessments were conducted at baseline and 7 weeks after baseline assessment. The instruments have been adapted and validated for use in Pakistan. Blinding was ensured during assessments through LHW instructing participants not to disclose their allocation status. In case of disclosure the assessments were reschedule through the other assessor.

\section{Anxiety and depression (primary outcome measure)}

Psychological distress in terms of states of anxiety and depression were measured with the Hospital Anxiety and Depression Scale (Zigmond \& Snaith, 1983; Mumford et al. 1991), an established scale consisting of 14 items. The HADS contains two sub-scales: HADS-A (anxiety, seven items and range 0-21) and HADS-D (depression, seven items and range 0-21).
Higher scores indicate more severe symptoms of anxiety and/or depression. The HADS has been translated into Urdu, and showed satisfactory reliability and validity (Mumford et al. 1991).

\section{Psychological distress (screening instrument)}

This was measured by the GHQ at baseline assessment only (Goldberg \& Williams, 1988; Minhas \& Mubbashar, 1996). When used as a screening tool, the GHQ is usually scored bi-modally (i.e., $0-0-1-1$ ), with scores ranging from 0 to 12. In a previous study in Pakistan, a cut-off of 3 or higher has been reported to indicate clinically significant psychological distress (Minhas \& Mubbashar, 1996).

\section{Functioning (screening instrument)}

Disability was assessed using the 12-item intervieweradministered screener version of the WHO Disability Assessment Schedule (WHODAS 2.0) (World Health Organization, 2010). WHODAS 2.0 covers six domains (cognition, mobility, self-care, getting along, life activities and participation), and assesses difficulties people have during the last 30 days. Difficulties are scored on a five-point Likert scale as none, mild, moderate, 
severe or extreme. WHODAS 2.0 has been validated cross-culturally and is valid as a screening and outcome measure, displaying good sensitivity to change (Andrews et al. 2009; Sousa et al. 2010).

\section{Depressive disorder}

The Patient Health Questionnaire (PHQ-9) is a nineitem instrument measuring presence and severity of depressive disorder (Kroenke et al. 2001). As a severity measure, the PHQ-9 score ranges from 0 to 27, with each of the nine items scored from 0 (not at all) to 3 (nearly every day). The PHQ has been validated in Urdu (Ahmer et al. 2007).

\section{Post-traumatic stress symptoms}

PTSD symptoms were measured using the PTSD Checklist for DSM-5 (Weathers et al. 2013). This 20-item checklist corresponds with the 20 symptoms of the DSM-5 PTSD diagnosis. Items were rated on a 0-4 scale, with a total severity score of 80 . The previous version of the PCL based on DSM IV PTSD symptoms, the PCL-C, has been used previously in Pakistan (Khalily et al. 2012). The PCL-5 was adapted to ask for symptoms in the last week (rather than month) to enhance sensitivity to change.

\section{Psychological outcome profiles (PSYCHLOPS)}

PSYCHLOPS consists of four questions (Ashworth et al. 2004), covering three domains: problems (two questions), function (one question) and wellbeing (one question). Responses are scored on an ordinal sixpoint scale producing a maximum score of 18 (6 points per domain). Lower scores indicate better psychological profile. PSYCHLOPS gave participants the opportunity to identify problems they wish to address and discuss during group session. Although PSYCHLOPS has not been validated in South Asian context, the tool has shown good convergent validity, satisfactory internal consistency with measures of psychological distress, and high sensitivity to change (Ashworth et al. 2009).

Adverse life events: Potentially traumatic events, day-to-day life events, and demographic information was also collected to compare the two arms for major baseline differences (Mollica et al. 1992; Rahman et al. 2003).

\section{Process evaluation}

The process evaluation involved mixed-methods process monitoring and semi-structured process evaluation interviews. Process monitoring involved analysis of supervision records and assessments of layhelper competency. The lay-helpers were assessed by four independent assessors through application of a specially developed competency rating tool that evaluated: (a) counselling skills and (b) use of PM+ strategies with participants through direct observation of specially designed role plays. Competency was rated using a five-point Likert scale ranging from 0 (not done) to 5 (excellent).

The qualitative evaluation explored questions relating to intervention acceptability through targeted semistructured interviews with key informants following an established approach for applied mental health research in humanitarian settings (Applied Mental Health Research Group, 2013; Green \& Thorogood, 2014). Interviews followed a semi-structured topic guide developed for each category of key informant including intervention participants, lay-helpers, LHWs, family members of intervention participants and assessment team members. They were all interviewed through the semi structured topic guide on feasibility/acceptability of the trial procedures in the community. Interviews were documented verbatim in a written transcript for subsequent analysis.

\section{Data analysis}

Since this was a feasibility trial, no power calculations were carried out (Leon et al. 2011). Feasibility testing of all the components of training, delivery and supervision requires the LHWs have a sufficient case-load. The sample size allowed each LHW to have six cases (one group), which is sufficient for a feasibility study.

We carried out intention-to-treat analysis to assess the intervention effect (participant were randomised and analysed irrespective of whether or not they received the allocated intervention as long as they completed the end point assessment). A linear mixed model was used for the analysis of continuous outcomes which had treatment as a fixed effect, baseline measurement of the primary outcome as a covariate, and cluster as random effect. The treatment difference in least squares means (treatment effect) between the two arms together with its $95 \%$ confidence interval was derived from the mixed model.

All qualitative data were analysed using thematic content analysis (Ritchie et al. 1994; Applied Mental Health Research Group, 2013; Green \& Thorogood, 2014) relevant to applied research. This involved researchers familiarising themselves with interview transcripts, coding transcripts by themes and subthemes, and finalising coding through consensus. A document containing thematic categories was then reviewed alongside interview transcripts to identify quotes to illustrate key themes. All analysis was 
conducted in the original language, with only the quotes presented here translated into English.

Ethical approval was obtained from the local Ethics Review Board at the Lady Reading Hospital and the WHO Ethical Review Committee. Participants were only enrolled after providing voluntary written informed consent, which included information on trial procedure, confidentiality, data management and reporting.

\section{Results}

A total of 134 participants referred by their respective LHWs were approached for screening. Fourteen participants declined participation before screening. The 120 participants who agreed to participate were screened on the two screening instruments after informed consent. After screening positive, 119 participants were invited for the trial. Of the 119, 59 participants in 10 LHW catchment areas were in the intervention arm, and 60 participants in 10 LHW catchment areas were in the control arm. Seven participants of the 119 randomised (6\%) were lost to follow-up. See Fig. 1 for a detailed consort flow diagram. Table 1 shows the sample characteristics, and demonstrates the treatment arms were well balanced at baseline for demographic variables.

Table 2 summarises results for the primary and secondary outcomes in the intervention and control arms on intention-to-treat analysis. On the HADS score (primary outcome measure), there was a difference in the scores of both arms with the intervention arm mean HADS score 4.73 less than the control group (95\% CI: $(-7.41$ to $-2.06, p=0.001)$. This difference in scores was observed for the separate anxiety and depression scores, at 2.62 [95\% CI: $(-4.46$ to $-0.77, p=0.008$ ] and 2.48 [95\% CI: $(-4.00$ to $-0.97, p=0.002]$, respectively. Similarly on the WHODAS (functionality), PSYCHLOPS, PTSD symptoms (PCL) and depressive disorder (PHQ) scores showed a trend in favour of intervention.

Although the study was not powered to detect clinically significant differences on outcome measures, the results indicated that $\mathrm{PM}+$ had the potential to improve functioning, symptoms of anxiety and depression.

\section{Process evaluation}

Process monitoring demonstrated that participants showed good levels of intervention adherence with $36 / 59(61 \%)$ attending all five sessions; and 14/59 $(24 \%), 4 / 59(6.8 \%), 3 / 59(5 \%)$ and $1 / 59$ completing four, three, two and one session/s, respectively. Initially, both lay-helpers achieved unsatisfactory results in their competency assessments. Additional
Table 1. Demographic variables between intervention and control group

\begin{tabular}{|c|c|c|}
\hline Variables & $\begin{array}{l}\text { Intervention group } \\
\qquad(N=59) n(\%)\end{array}$ & $\begin{array}{l}\text { Control group } \\
(N=60) n(\%)\end{array}$ \\
\hline \multicolumn{3}{|l|}{ Age } \\
\hline 25 years or less & $21(36)$ & $16(27)$ \\
\hline 26-35 years & $18(31)$ & $19(32)$ \\
\hline $36-45$ years & $18(31)$ & $21(35)$ \\
\hline 46 years or more & $2(3)$ & $4(7)$ \\
\hline \multicolumn{3}{|l|}{ Marital status } \\
\hline Never married & $7(12)$ & $7(12)$ \\
\hline Currently married & $41(70)$ & $47(78)$ \\
\hline Separated & $3(5)$ & $3(5)$ \\
\hline Widowed & $8(14)$ & $3(5)$ \\
\hline \multicolumn{3}{|l|}{ Education } \\
\hline None & $41(70)$ & $41(68)$ \\
\hline Primary & $9(15)$ & $10(17)$ \\
\hline Secondary & $6(10)$ & $6(10)$ \\
\hline 10 years or above & $3(5)$ & $3(5)$ \\
\hline \multicolumn{3}{|l|}{ Occupation } \\
\hline Paid work & $10(17)$ & $16(27)$ \\
\hline House keeping & $48(81)$ & $41(68)$ \\
\hline \multicolumn{3}{|c|}{ Respondent husband's occupation } \\
\hline Paid work & $19(43)$ & $13(28)$ \\
\hline Self-employed & $18(41)$ & $22(47)$ \\
\hline Unemployed & $1(2)$ & $2(4)$ \\
\hline $\begin{array}{l}\text { Financially } \\
\text { empowered }\end{array}$ & $27(46)$ & $26(43)$ \\
\hline $\begin{array}{l}\text { Nuclear family } \\
\text { structure }\end{array}$ & $16(27)$ & $16(27)$ \\
\hline \multicolumn{3}{|l|}{ Family size } \\
\hline $\begin{array}{l}\geq 2 \text { children } \\
\text { younger than } 7 \\
\text { years old }\end{array}$ & $17(29)$ & $22(37)$ \\
\hline
\end{tabular}

targeted training and supervision (2 days over Skype sessions and visits) was therefore provided to support in areas where their scores were low, alongside additional practice sessions in the field under intensive supervision. Following this the lay-helpers were re-assessed and deemed competent to deliver Group $\mathrm{PM}+$.

Key objectives of the qualitative interviews were to explore: The acceptability of the intervention to key stakeholders, the feasibility of LHWs supporting integration of the intervention into their routine scope of work and identifying barriers and challenges to further scale-up. Interviews were conducted with two layhelpers, five participants who completed the sessions, four family members of the completing participants, three LHWs and two assessment team members. The number of interviews was predetermined and weighted for each category of respondent. Due to time constraints data collection did not reach saturation (no new information after data saturation). 
Table 2. Comparison of outcomes between control and intervention groups on intention to treat analysis

\begin{tabular}{|c|c|c|c|c|c|c|c|}
\hline \multirow[b]{2}{*}{$\begin{array}{l}\text { Primary and } \\
\text { secondary outcomes }\end{array}$} & \multirow[b]{2}{*}{ Time } & \multirow[b]{2}{*}{$N$} & \multirow[b]{2}{*}{$\begin{array}{c}\text { Intervention } \\
\text { group [Mean (SD)] }\end{array}$} & \multirow{2}{*}{\multicolumn{2}{|c|}{$\begin{array}{cc} & \text { Control } \\
& \text { group } \\
N & {[\text { Mean (SD)] }}\end{array}$}} & \multicolumn{2}{|c|}{ Linear mixed model } \\
\hline & & & & & & $\begin{array}{c}\text { Difference in least } \\
\text { squares mean }(95 \% \mathrm{CI})\end{array}$ & $p$-value \\
\hline \multirow{2}{*}{$\begin{array}{l}\text { Hospital anxiety \& } \\
\text { depression rating } \\
\text { scale (depression } \\
\text { and anxiety } \\
\text { combined) }\end{array}$} & Baseline & 59 & $20.15(7.13)$ & 60 & $24.15(7.58)$ & $-4.65(-7.35$ to -1.95$)$ & 0.0009 \\
\hline & One week post intervention & 54 & $15.70(9.04)$ & 58 & $23.21(8.32)$ & & \\
\hline \multirow{2}{*}{$\begin{array}{l}\text { Hospital anxiety } \\
\text { rating scale } \\
\text { (anxiety score) }\end{array}$} & Baseline & 59 & $10.81(3.68)$ & 60 & $13.13(3.94)$ & $-2.62(-4.37$ to -0.86$)$ & 0.0039 \\
\hline & One Week post intervention & 54 & $7.59(4.66)$ & 58 & $11.52(4.59)$ & & \\
\hline \multirow{2}{*}{$\begin{array}{l}\text { Hospital depression } \\
\text { rating scale } \\
\text { (depression score) }\end{array}$} & Baseline & 59 & $9.34(4.38)$ & 60 & $11.02(4.32)$ & $-2.48(-4.00$ to -0.96$)$ & 0.0016 \\
\hline & One week post intervention & 54 & $8.11(5.13)$ & 58 & $11.69(4.42)$ & & \\
\hline \multirow{2}{*}{$\begin{array}{l}\text { WHO DAS } \\
\text { (functionality) }\end{array}$} & Baseline & 59 & $30.24(6.62)$ & 60 & $31.92(7.20)$ & $-5.37(-8.97$ to -1.76$)$ & 0.0040 \\
\hline & One week post intervention & 54 & $24.44(8.90)$ & 58 & $30.86(8.64)$ & & \\
\hline \multirow[t]{2}{*}{ PSYCHLOPS } & Baseline & 55 & $14.69(3.31)$ & 60 & $15.63(3.39)$ & $-4.49(-6.41$ to -2.58$)$ & $<0.0001$ \\
\hline & One week post intervention & 54 & $9.22(4.97)$ & 57 & $14.21(3.98)$ & & \\
\hline \multirow{2}{*}{$\begin{array}{l}\text { PCL (PTSD } \\
\text { symptoms) }\end{array}$} & Baseline & 59 & $28.47(15.80)$ & 60 & $36.53(16.73)$ & $-2.79(-9.51$ to 3.94$)$ & 0.4128 \\
\hline & One week post intervention & 54 & 17.65 (15.59) & 58 & $24.02(16.26)$ & & \\
\hline \multirow{2}{*}{$\begin{array}{l}\text { PHQ (generalised } \\
\text { distress) }\end{array}$} & Baseline & 59 & $11.42(5.71)$ & 60 & $13.23(6.92)$ & $-1.06(-3.59$ to 1.48$)$ & 0.4112 \\
\hline & One week post intervention & 54 & $10.06(6.45)$ & 58 & $12.05(6.09)$ & & \\
\hline
\end{tabular}

Interviewees raised common themes which are summarised in Table 3. Overall lay-helpers, participants and their families expressed satisfaction with Group $\mathrm{PM}+$, identifying its ability to address problems relating to participants' perceived psychological well-being and daily functioning. Furthermore, respondents felt that lay-helpers developed good rapport with the participants.

A barrier identified by participants and family members was the duration of sessions $(2 \mathrm{~h})$. Furthermore, participants expectation of monetary incentives to attend sessions (in line with the routine practice of many international organisation programmes), led to difficulties motivating participants to attend, and may have influenced lower levels of intervention attendance. Finally, confidentiality issues arose in sessions containing multiple participants from the same household. Consequently, many participants felt uncomfortable disclosing their problems to the group, instead seeking to discuss these with the lay-helper separately during breaks.

\section{Discussion}

This mixed-method study assessed the acceptability and feasibility of Group PM+ through a feasibility cluster randomised controlled trial. The results show that layhelpers can be trained to achieve the desired competency to successfully deliver the intervention in community under supervision. Overall, intervention uptake was good, with Group PM+ considered useful by participants, their families, and lay-helpers. The outcome evaluation, which was not powered, nonetheless indicated relevant improvements in symptoms of depression, anxiety; general psychological profile and functioning. Barriers identified included confidentiality issues, which suggest that sessions need to be comprised of women from different households. A recommendation is that the length of the session be reduced through shortening session breaks to minimise the time that females were away from household responsibilities.

A major strength of this study is that it has been conducted in a post-conflict area with adequate recruitment and low dropout rate. The intervention was 
Table 3. Qualitative interview results

\begin{tabular}{lll}
\hline Objective & Theme & Quote (source)
\end{tabular}

Acceptability to participants Participants learnt useful skills to manage their problems

Acceptability to families

Acceptability to lay-helpers

Feasible for LHWs to act as intervention facilitators

Barriers and challenges
Recognisable improvement in condition

Lay-helpers learnt the skills

LHWs respected and trusted in the community

Confidentiality issues

Monetary expectations

Long session duration
This was a very good experience. I am satisfied. We learned some techniques here that we didn't knew before. We discussed our problem in groups and tried to solve them (Client)

This was easy for me to implement the skills because these were solving my problems and my tension and the heaviness of my head improved, so I practised them regularly (Client)

I had very good relation with my helper and I liked her because she came for us, we learned a lot that changed our lives, I trusted her and told her all my problems, our tensions were reduced because of her, she taught us such skills that we didn't knew, and those skills solved a lot of our problems, it changed our behaviours (Client)

I think this is a very good program because the participant from our house improved a lot (Client family)

My family realised that these sessions are regarding health so I was allowed to attend the sessions and they trusted the lay-helper (Client)

At the start it was difficult because I have no idea of the work. But then it all went well. I not only managed peoples' problems and learnt the skills but also learned to manage my own routine problems (Lay-helper)

Very friendly, they trusted us, they frankly shared their problems with us. If they could not share any problem during the session in front of other participants they spoke to us during break time (Lay helper)

The participant realised that it is working and their small problems started resolving, this motivated them to continue (Lay helper)

I had a very good experience with the program; as all of the participants gathered in my health house, collectively listened everyone problems and then discussed the solutions. I even learnt new skills which improved my own health as well (LHW)

I am officially working in this catchment area, so all these people know me and trust me. That's the reason they send their women to my house (LHW)

If in any session there were two or three participants from the same house that made it difficult to let the participants share their problems (Lay helper)

I was not able to share my problems because of my family member in the same group (Client)

Participants wanted some monetary incentives and when it was not provided they lost interest and they were not punctual. (Lay helper)

Everyone believed that there would be some monetary incentives for the participants, but there was none (Client)

There was plenty of household chores to be done in the house, so at times the family got annoyed, the session duration was too long (Client)

The sessions were too long and families have reservations, as the participants have to do work back home (Lay helper) 
found to be acceptable to the local community and LHWs. Furthermore, there was a high trial retention rate $(94 \%)$, which further suggests community acceptability of the intervention (Ehlers et al. 2005; Rachman et al. 2008). This could be due to the accessibility of the intervention in the community, which reduced the potential stigma associated with seeking mental health support (Rahman et al. 2013). Indeed, good retention was also found in a trial of group interpersonal psychotherapy in Uganda (Bolton et al. 2003). The feasibility of procedures and acceptability of the intervention to the community, LHWs and health system show that larger scale definitive trials are possible in the setting.

LHWs successfully facilitated the introduction of lay-helpers to the community and invited participants to the sessions. They were ideal hosts for Group PM+ as they are trusted and respected in the communities, overcoming a barrier to accessing women in need. Rural Swat may be considered a highly conservative society and without the LHWs as gatekeepers, community members are unlikely to trust and accept the research procedures and new health interventions (Mohmand \& Gazdar, 2007).

The group format of the intervention had some inherent challenges; notably that women were reluctant to discuss their problems in the presence of family members. For the definitive trial this challenge will be addressed by separating family members into different $\mathrm{PM}+$ groups. In addition, the long duration of each session for the definitive trial will be managed by either reducing the duration of breaks or taking them at the end of the session, according to the preference of each group.

The lay-helpers were recruited from the local area with the aim of ensuring acceptability and an ability to relate well to their participants. There are data showing that participants can have preference for delivery agents from within the communities over outside specialists, as they are easily accessible and reduce the stigma attached to help-seeking (Singla et al. 2014). Furthermore, local selection is considered to enhance the potential for future intervention scale-up. The layhelpers were graduates with no prior experience of mental health interventions, enabling access to a large pool of potential persons to take on this role. In addition, locally embedded lay-helpers could be considered more conscious of the local context, including awareness of cultural norms and sensitivity to potential security concerns.

The supervision structures are potentially scalable, with a small number of trained specialists in another centre/city providing group-supervision to many layhelpers through video calls. Additionally, the group format of supervision enabled lay-helper peer support and supervision, which was found to be important for managing difficult situations arising during field activities, including lay-helpers emotional wellbeing. Training of lay-helpers was followed by four weeks of practice cases with weekly group supervision, therefore to enhance transfer of skills, more emphasis on experiential components and role-plays should be considered.

In conclusion, the current study shows encouraging results regarding the feasibility and acceptability of the Group PM+ intervention delivered by lay-helpers. The intervention showed improvement in depression, anxiety and functioning, although the small sample size means the results need to be interpreted with caution, with a larger scale definitive trial required to demonstrate intervention effectiveness.

\section{Supplementary Material}

The supplementary material for this article can be found at https://doi.org/10.1017/S2045796017000336

\section{Acknowledgements}

We are grateful to all the women who participated in this study and to the LHWs. We are also thankful to the district health administration for providing logistical support.

\section{Financial Support}

The study was funded by the Office of Foreign Disaster Assistance (OFDA). The authors alone are responsible for the views expressed in this article and they do not necessarily represent the views, decisions or policies of the institutions.

\section{Conflicts of Interest}

None.

\section{Ethical Standard}

The authors assert that all procedures contributing to this work comply with the ethical standards of the relevant national and institutional committees on human experimentation and with the Helsinki Declaration of 1975, revised 2008.

\section{Authorship}

Research was conceptualised by AR \& MvO. All authors have reviewed and approved the final manuscript for submission. 


\section{Availability of Data and Materials}

Raw data are available as additional supporting files.

\section{References}

Ahmer S, Faruqui RA, Aijaz A (2007). Psychiatric rating scales in Urdu: a systematic review. BMC Psychiatry 7, 1.

Allden K, Poole C, Chantavanich S, Ohmar K, Aung NN, Mollica RF (1996). Burmese political dissidents in Thailand: trauma and survival among young adults in exile. American Journal of Public Health 86, 1561-1569.

Andrews G, Kemp A, Sunderland M, Von Korff M, Ustun TB (2009). Normative data for the 12 item WHO Disability Assessment Schedule 2.0. PLOS ONE 4, e8343.

Applied Mental Health Research Group (2013). Design, Implementation, Monitoring, and Evaluation of Mental Health and Psychosocial Assistance Programs for Trauma Survivors in Low Resource Countries; A User's Manual for Researchers and Program Implementers. John Hopkins University Bloomberg School of Public Health: Baltimore, MA.

Ashworth M, Shepherd M, Christey J, Matthews V, Wright K, Parmentier H, Robinson S, Godfrey E (2004). A client-generated psychometric instrument: the development of 'PSYCHLOPS'. Counselling and Psychotheraphy Research 4, 27-31.

Ashworth M, Evans C, Clement S (2009). Measuring psychological outcomes after cognitive behaviour therapy in primary care: a comparison between a new patient-generated measure 'PSYCHLOPS' (Psychological Outcome Profiles) and 'HADS' (Hospital Anxiety and Depression Scale). Journal of Mental Health 18, 169-177.

Bhui K, Abdi A, Abdi M, Pereira S, Dualeh M, Robertson D, Sathyamoorthy G, Ismail H (2003). Traumatic events, migration characteristics and psychiatric symptoms among Somali refugees - preliminary communication. Social Psychiatry and Psychiatric Epidemiology 38, 35-43.

Bile KM, Hafeez A (2009). Crisis in the Swat Valley of Pakistan: need for international action. Lancet 374, 23.

Bolton P, Bass J, Neugebauer R, Verdeli H, Clougherty KF, Wickramaratne P, Speelman L, Ndogoni L, Weissman M (2003). Group interpersonal psychotherapy for depression in rural Uganda: a randomized controlled trial. JAMA 289, 3117-3124.

Craig G, Corden A, Thornton P (2000). Safety in social research. Social Research Update 29, 68-72.

Cuijpers P, Van Straten A, Warmerdam L, Smits N (2008). Characteristics of effective psychological treatments of depression: a metaregression analysis. Psychotherapy Research 18, 225-236.

Dawson KS, Bryant RA, Harper M, Kuowei Tay A, Rahman A, Schafer A, van Ommeren M (2015). Problem Management Plus (PM+): a WHO transdiagnostic psychological intervention for common mental health problems. World Psychiatry 14, 354-357.

Ehlers A, Clark DM, Hackmann A, McManus F, Fennell M (2005). Cognitive therapy for post-traumatic stress disorder: development and evaluation. Behaviour Research and Therapy 43, 413-431.
Ellsberg M, Jansen HA, Heise L, Watts CH, Garcia-Moreno C (2008). Intimate partner violence and women's physical and mental health in the WHO multi-country study on women's health and domestic violence: an observational study. The Lancet 371, 1165-1172.

George C, Kanakamma LG, John J, Sunny G, Cohen A, De Silva MJ (2012). Post-tsunami mental health: a cross-sectional survey of the predictors of common mental disorders in South India 9-11 months after the 2004 Tsunami. Asia-Pacific Psychiatry 4, 104-112.

Goldberg D, Williams P (1988). A User's Guide to the General Health Questionnaire. NFER-Nelson: Windsor, Berks.

Green J, Thorogood N (2014). Qualitative Methods for Health Research. SAGE Publishing: London, UK.

Hafeez A, Mohamud BK, Shiekh MR, Shah SAI, Jooma R (2011). Lady health workers programme in Pakistan: challenges, achievements and the way forward. Journal of the Pakistan Medical Association 61, 210.

Inter-Agency Standing Committee (2007). IASC Guidelines on Mental Health and Psychosocial Support in Emergency Settings. Inter-Agency Standing Committee: Geneva, Switzerland.

Kakuma R, Minas H, van Ginneken N, Dal Poz MR, Desiraju K, Morris JE, Saxena S, Scheffler RM (2011). Human resources for mental health care: current situation and strategies for action. Lancet 378, 1654-1663.

Khalily MT, Gul S, Mushtaq R, Jahangir SF (2012). To examine delayed PTSD symptomatology over time among trauma survivors in Pakistan. The Online Journal of Counselling and Education 1, 1-11.

Khan MN, Chiumento A, Dherani M, Bristow K, Sikander S, Rahman A (2015). Psychological distress and its associations with past events in pregnant women affected by armed conflict in Swat, Pakistan: a cross sectional study. Conflict and Health 9, 37.

Kroenke K, Spitzer RL, Williams JB (2001). The PHQ-9: validity of a brief depression severity measure. Journal of General Internal Medicine 16, 606-613.

Leon AC, Davis LL, Kraemer HC (2011). The role and interpretation of pilot studies in clinical research. Journal of Psychiatric Research 45, 626-629.

Minhas F, Mubbashar M (1996). Validation of General Health Questionnaire (GHQ-12) in primary care settings of Pakistan. Journal of the College of Physicians and Surgeons Pakistan 6, 133-136.

Mohmand S, Gazdar H (2007). Social structures in rural Pakistan. In Determinants and Drivers of Poverty Reduction and ADB's Contribution in Rural Pakistan, p. 56. Asian Development Bank: Islamabad, Pakistan.

Mollica RF, Caspi-Yavin Y, Bollini P, Truong T, Tor S, Lavelle J (1992). The Harvard Trauma Questionnaire: validating a cross-cultural instrument for measuring torture, trauma, and posttraumatic stress disorder in Indochinese refugees. The Journal of Nervous and Mental Disease 180, 111-116.

Mumford D, Tareen I, Bajwa M, Bhatti M, Karim R (1991). The translation and evaluation of an Urdu version of the Hospital Anxiety and Depression Scale. Acta Psychiatrica Scandinavica 83, 81-85.

Murray LK, Dorsey S, Bolton P, Jordans MJ, Rahman A, Bass J, Verdeli H (2011). Building capacity in mental health 
interventions in low resource countries: an apprenticeship model for training local providers. International Journal of Mental Health Systems 5, 1.

Pakistan Bureau of Statistics (2016). District at a glance Swat. http://www.pbs.gov.pk/content/district-glance-swat. Accessed 20th July 2016.

Rachman S, Radomsky AS, Shafran R (2008). Safety behaviour: a reconsideration. Behaviour Research and Therapy 46, 163-173.

Rahman A, Iqbal Z, Harrington R (2003). Life events, social support and depression in childbirth: perspectives from a rural community in the developing world. Psychological Medicine 33, 1161-1167.

Rahman A, Malik A, Sikander S, Roberts C, Creed F (2008). Cognitive behaviour therapy-based intervention by community health workers for mothers with depression and their infants in rural Pakistan: a cluster-randomised controlled trial. Lancet 372, 902-909.

Rahman A, Fisher J, Bower P, Luchters S, Tran T, Yasamy MT, Saxena S, Waheed W (2013). Interventions for common perinatal mental disorders in women in low-and middle-income countries: a systematic review and meta-analysis. Bulletin of the World Health Organization 91, 593-601I.

Ritchie J, Spencer L, Bryman A, Burgess R (1994). Analysing Qualitative Data. Routledge: London.

Rome S (2010). Crisis and reconciliation in Swat. Pakistaniaat a Journal of Pakistan Studies 3, 53-79.

Singla D, Lazarus A, Atif N, Sikander S, Bhatia U, Ahmad I, Nisar A, Khan S, Fuhr D, Patel V (2014). 'Someone like us': delivering maternal mental health through peers in two South Asian contexts. Journal of Affective Disorders 168, 452458.

Sousa RM, Dewey ME, Acosta D, Jotheeswaran A, Castro-Costa E, Ferri CP, Guerra M, Huang Y, Jacob K, Pichardo JGR (2010). Measuring disability across cultures - the psychometric properties of the WHODAS II in older people from seven low-and middle-income countries. The
10/66 Dementia Research Group population-based survey. International Journal of Methods in Psychiatric Research 19, 117.

Steel Z, Chey T, Silove D, Marnane C, Bryant RA, van Ommeren M (2009). Association of torture and other potentially traumatic events with mental health outcomes among populations exposed to mass conflict and displacement: a systematic review and meta-analysis. JAMA 302, 537-549.

Tol WA, Barbui C, Galappatti A, Silove D, Betancourt TS, Souza R, Golaz A, van Ommeren M (2011). Mental health and psychosocial support in humanitarian settings: linking practice and research. Lancet 378, 1581-1591.

Tol WA, Barbui C, van Ommeren M (2013). Management of acute stress, PTSD, and bereavement: WHO recommendations. JAMA 310, 477-478.

Ventevogel P, van Ommeren M, Schilperoord M, Saxena S (2015). Improving mental health care in humanitarian emergencies. Bulletin of the World Health Organization 93, 666-666a.

Weathers FW, Litz BT, Keane TM, Palmieri P, Marx B, Schnurr P (2013) The PTSD Checklist for DSM-5 (PCL-5). National Center for PTSD. http://www.ptsd.va.gov/ professional/assessment/adult-sr/ptsd-checklist.asp. Accessed June 232016.

World Health Organization (2007). Mental health assistance to the populations affected by the Tsunami in Asia. http:// www.who.int/mental_health/resources/tsunami/en/index1. html. Accessed 20th July 2016.

World Health Organization (2010). Measuring health and disability: Manual for WHO disability assessment schedule WHODAS 2.0. World Health Organization: Geneva, Switzerland.

Yalom ID, Leszcz M (2005). The Theory and Practice of Group Psychotherapy. Basic books, A Member of the Perseus Books Group: New York.

Zigmond AS, Snaith RP (1983). The hospital anxiety and depression scale. Acta Psychiatrica Scandinavica 67, 361-370. 